\title{
Mitosis-Karyorrhexis Index
}

National Cancer Institute

\section{Source}

National Cancer Institute. Mitosis-Karyorrhexis Index. NCI Thesaurus. Code C106317.

A tumor cell proliferation measurement represented by the number of cells in mitosis plus the number of cells in karyorrhexis per 5000 cells. 